\title{
Development of English Linguistics and Its Linking with English Education in Modern Colleges
}

\author{
Fei Wu \\ Department of Maritime Technology, Tianjin Maritime College, Tianjin, 300350, China.
}

Keywords: English Linguistics, English Education, Modern Colleges, Linking.

\begin{abstract}
This paper analyzes the English linguistics and its linking with English education in modern colleges. China as a big country of English teaching should re-examine the concept of English education and practice. Based on the current context of global localization, this paper will focus on the shortcomings of the English education in China, and point out the necessity of its reform in China, and put forward some suggestions on the specific operation. We propose that teacher should base in student's actual difference uses has the difference course content, designs the different plan of basic instruction and the teaching goal can arouse student's enthusiasm and the initiative fully, thus enables the student to be able obtains certain enhancement and the development compared to the original knowledge reserve and the structure. The proposed method is effect for education effectiveness.
\end{abstract}

\section{Introduction}

Carries on the language education to the student at the same time, naturally integrates the education for all-around development appropriately can stimulate to transfer the student well study English the strong interest and the enthusiasm, can to the teaching material content understand thoroughly and can grasp to the language knowledge solidly as well can maximum limit enhance the student to express, the utilization language ability actually which causes the language teaching and the education for the all-around development complements each other that promotes mutually. In this context, China as a big country of English teaching should re-examine the concept of English education and practice. Based on the current context of global localization, this paper will focus on the shortcomings of the English education in China, and point out the necessity of its reform in China, and put forward some suggestions on the specific operation [1-3].

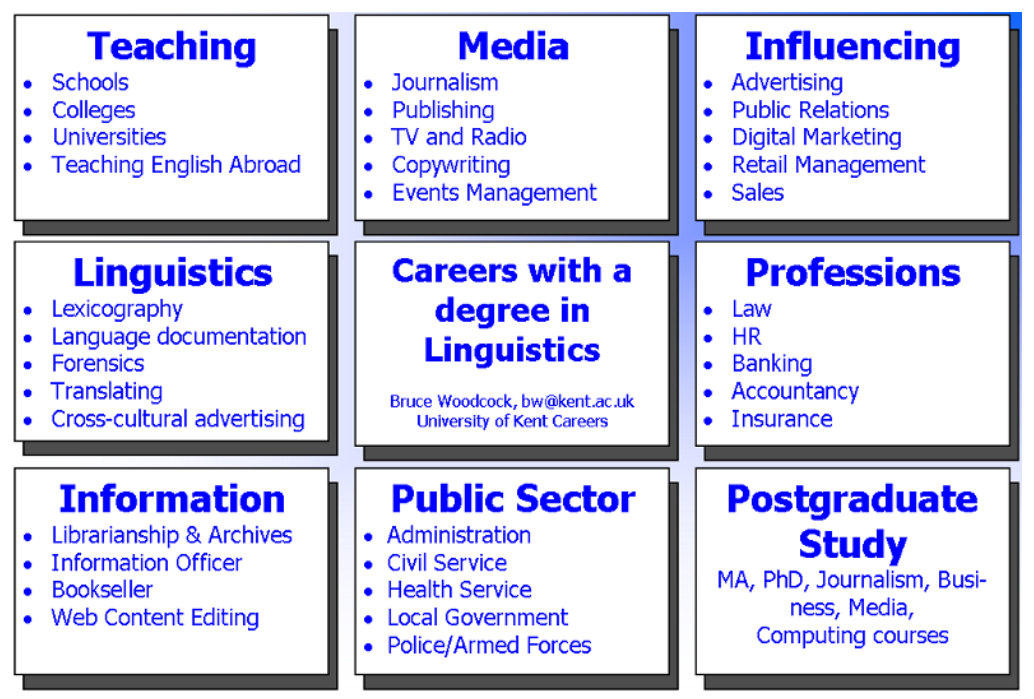

Fig. 1 Principles of Education in Modern Colleges

In accordance with the relevant provisions of ministry of education, higher vocational education to cultivate talents should be skilled and applied practical, social, senior technology talents. Higher vocational students are learning English is in the service of the professional and technical, engaged in 
the professional services for the future, is not like ordinary college English major students to study English, in order to work in the translation or the English teaching. Therefore, the higher vocational English course should stress the cultivation of the students' English ability while teaching should be practical, targeted, etc. The theory of the multiple intelligences suggests that different people have different combinations of intelligences and it is because of the different combination of intelligent people, so I decided to different people with different talents. In the process of occupation education foundation, teachers should correctly treat students there are some differences in the objective fact, the basis of good students to learn very easily but, poor students will lead to difficulties in the process of learning. The teacher bases in student's actual difference uses has the difference course content, designs the different plan of instruction and the teaching goal can arouse student's enthusiasm and the initiative fully, thus enables the student to be able obtains certain enhancement and the development compared to the original knowledge reserve and the structure. The teacher also must fully understand each student's intelligent characteristic as well as the knowledge foundation situation, in order to can truly carry on the lamination teaching to student's study situation.

\section{Our Proposed Methodology}

\subsection{English Linguistics}

Linguistics is a wide range of research, English is a language first followed by a discipline, English itself is the study of English language, which can also be called English linguistics, and linguistics of the general theory of the English teaching guidance can effectively improve the teaching of science and students English-related issues are easier to grasp [4-6].

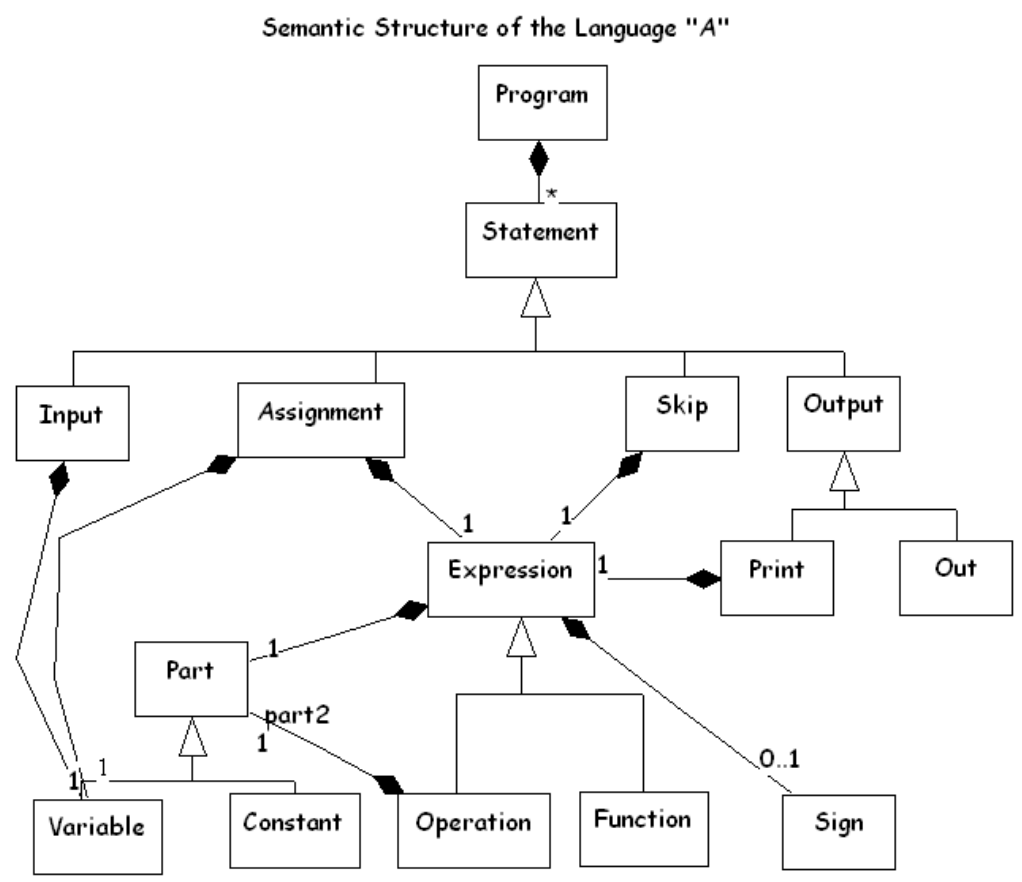

Fig. 2 The Systematic Architecture of the English Linguistics

The current various countries have conducted the research to English language, regarding once colonial country, to the language research is the historical inheritance, and already developed into English our country important language, has provided the more power support for our country. Regarding the non-English-speaking country, carries on English linguistics the research, on the one hand is carries on the communication and the exchange for can well and the English-speaking country, on the other hand, may through to language research then understanding English-speaking country political record and the custom culture from the following aspects.

$>$ The theory of cohesion in linguistics mainly refers to the connection of the vocabulary through connection, substitution, omission and so on, so that the discourse can express the 
general corresponding meaning, the teacher can apply the theory to the students' reading and listening ability and let the students in the analysis of the sentence by understanding the key words to clarify the meaning of the sentence.

$>$ Metaphor is an important cognitive rule of human language that people will use the language and concepts known to the concept while of unknown vocabulary comprehension that plays an important role in reading as cognitive metaphor theory of linguistics and translation in English listening teaching.

$>$ Colleges and universities tend to teach English as a second language, and input theory is an important theory of the second language learning in linguistics. In layman's terms, when the learners are placed in an environment slightly higher than their own language ability, language skills are more likely to be improved, and also our country lacks a suitable English learning environment, so teachers need to try to create a suitable cultural environment for students.

\subsection{English Education Suggestions}

With the "English education" concept, that is, to cultivate the social scale of applied and compound talents, to measure today's English majors, as a whole, there is a very obvious "academic", "linguistic" and "Second language" tendencies, teach fancy, learn not solid. From the students who see, the more common problems are: the basic skills of general English weak, poor Chinese, narrow knowledge, independent work ability, style impetuous, lax, the root cause in the lack of truth and pragmatism and emboldened while reflecting the majority of the problem of teaching.

Cross-cultural communication is not a one-way indoctrination, but in the principle of equality, the two sides hold different languages and some cultural individual exchanges. Therefore, cross-cultural communication cannot be confined to the "understanding" of the exchange object, but also with the "cultural sharing" of the exchange object and the "cultural impact" of the exchange objects and in some cases, successful communication is more important. Paying more attention to English in the teaching, the orthodox to unorthodox, from one yuan to the diverse development and change focus on standard English and China English, British and American culture and Chinese culture and prompted China's English teaching paradigm localization of shift in the global atmosphere, therefore, we give the suggestions for the English education as the follows.

$>$ China's English education researchers and practitioners should rationally study and analyze some foreign language education theory that should follow the principle of local conditions, according to national conditions, teaching and learning situation, to deal with the "external absorption" and "based on the local" relationship. English teaching methodology research should carry on in a higher level and must in the model correlation discipline research results foundation, consider fully our country English study the particularity, learner's characteristic, the teachers level and other teaching environment, the discussion and the design conforms to the different level and the disparity in age learner demand teaching method.

$>$ Encourage English education development theory researchers and practitioners, also suitable for variety characteristics of English classroom that reflects the fact that theory comes from practice. Teachers development teaching theory helps to break the development process of the theory and practice of isolated situation, encourage teachers reflect on their own professional and classroom practice constantly and build the grounded theory that achieve the professional development of teachers to improve the quality of English education in our country finally.

English teaching materials should not be limited to the culture of the United States and other western countries and also should increase the proportion of outstanding foreign culture it is recommended that the world's outstanding culture is included. Secondly, the integration of the local cultural content while not only to ensure the quantity, but also to filter the essence of the traditional Chinese culture. 


\subsection{College Education Suggestions}

We must raise the great amount the innovation talented person, must reform the existing education pattern, the implementation innovation education that provides for the student loose and enables its innovation potential to stimulate, the development and the growth good environment. Only then all established in the school and the society for the student has made the suitable raise innovation spirit and the innovation ability innovation environment could truly train the innovation talented person who our country socialist construction urgently needed. Therefore, related course system of science, perfect or not, is the key to the work quality of cultural quality education. Therefore, focusing on the mentioned challenges, we provide the suggestions as the follows.

$>$ In view of the current situation of the university's cultural quality education curriculum, the relevant departments of the school must first do is to clarify the curriculum objectives, and always put the curriculum goal as the guiding ideology of curriculum design, so to carefully design the curriculum system.

$>$ The management content is not merely a teaching, but also must include the curriculum the production link, like curriculum goal determination, curriculum content choice and so on this is the curriculum effective implementation precondition. In addition, this specialized agency also must carry out the general culture education for all-around development thoroughly the fundamental research, the realization theory and the actual organic synthesis pays attention to the domestic and foreign correlation domain as necessary the research trend grasps the most front the information.

Only through a variety of teaching methods (subject teaching, student independent or group research study, classroom reports, discussions, etc.), so that each student really involved in, to stimulate thinking and to encourage expression and debate in order to create a "natural critical the learning environment ". The prerequisite for creating such a learning environment is the substantial input of teachers and students to cultural quality education.

\section{Summary}

This paper analyzes the English linguistics and its linking with English education in modern colleges. The foreign language classroom psychology environment is refers in take the instructors class as in unit's teaching activity, and experiences the interpersonal environment for the student sensation. The optimized foreign language classroom psychology environment is cultivates blue student psychology humanities mental the good beginning and cuts the human to select best. In the future, we will then apply the proposed method into the education scenarios to test the effect.

\section{References}

[1] Platt, Heidi. "Case theory and its application to language teaching." ITL-International Journal of Applied Linguistics 15.1 (2016): 31-45.

[2] Thuy, Nguyen Ho Hoang. "Teaching efl writing in Vietnam: Problems and solutions-a discussion from the outlook of applied linguistics." VNU Journal of Science: Foreign Studies 25.1 (2016).

[3] Bell, Nancy, and Anne Pomerantz. "Reconsidering language teaching through a focus on humor." EuroAmerican Journal of Applied Linguistics and Languages. E-JournALL 1.1 (2014): 31-47.

[4] Lyster, Roy, Kazuya Saito, and Masatoshi Sato. "Oral corrective feedback in second language classrooms." Language Teaching 46.1 (2013): 1.

[5] Oliver, Rhonda, Honglin Chen, and Stephen Moore. "Review of selected research in applied linguistics published in Australia (2008-2014)." Language Teaching 49.4 (2016): 513-548. 
[6] Weideman, Albert. "Themes and Styles of Doing Applied Linguistics." Responsible Design in Applied Linguistics: Theory and Practice. Springer International Publishing, 2017. 149-182. 